\title{
A Decomposition Approach for Manufacturing System Design
}

David S. Cochran, Jorge F. Arinez, James W. Duda, Joachim Linck

Production System Design Laboratory

Department of Mechanical Engineering

Massachusetts Institute of Technology

Cambridge, MA, U.S.A. 02139 


\begin{abstract}
Successful manufacturing system designs must be capable of satisfying the strategic objectives of a company. There exist numerous tools to design manufacturing systems. Most frameworks, however, do not separate objectives from means. As a result, it is difficult to understand the interactions among different design objectives and solutions and to communicate these interactions. The research described in this paper develops an approach to help manufacturing system designers: (1) clearly separate objectives from the means of achievement, (2) relate low-level activities and decisions to high-level goals and requirements, (3) understand the interrelationships among the different elements of a system design, and (4) effectively communicate this information across a manufacturing organization. This research does so by describing a manufacturing system design decomposition (MSDD). The MSDD enables a firm to simultaneously achieve cost, quality, delivery responsiveness to the customer and flexibility objectives. The application section illustrates how the MSDD can be applied in conjunction with existing procedural manufacturing engineering.
\end{abstract}

Keywords: manufacturing system design, manufacturing strategy, axiomatic design

\title{
Introduction
}

Designing a manufacturing system to achieve a set of strategic objectives involves making a series of complex decisions over time [1]. Making these decisions in a way that supports a firm's high-level objectives requires an understanding of how detailed design issues affect the interactions among various components of a manufacturing system. This paper presents an axiomatic design-based decomposition of a general set of functional requirements and design parameters for a manufacturing system and explains how this decomposition can be used as an approach to aid engineers and managers in the design and operation of manufacturing systems.

In practice, designing the details of manufacturing systems (equipment design and specification, layout, manual and automatic work content, material and information flow, etc.) in a way that is supportive of a firm's business strategy has proven to be a difficult challenge. Because manufacturing systems are complex entities involving many interacting elements, it can be difficult to understand the impact of detailed, low-level deficiencies and change the performance of a manufacturing system as a whole.

Shingo [2] discusses the problem of optimizing individual operations as opposed to the overall process (referred to as manufacturing system herein). Hopp and Spearman describe the same problem, calling 
it a reductionist approach where the focus is on breaking a complex system into its more simple components and then analyzing each component separately [3]. They go on to point out that "too much emphasis on individual components can lead to a loss of perspective for the overall system," and that a more holistic approach can lead to better overall system performance.

The framework presented in this paper develops a tool to help manufacturing system designers (1)

clearly separate objectives from the means of achieving them, (2) relate low-level activities and decisions to high-level goals and requirements, (3) understand the interrelationships among the different elements of a system design, and (4) effectively communicate this information across the organization. The structure of the framework is based on axiomatic design.

The decomposition framework for manufacturing system design and control integrates several different disciplines such as plant layout design and operation, human work organization, ergonomics, equipment design, material supply, use of information technology, and performance measurement. The target industries of the framework are medium to high volume repetitive manufacturing companies.

\section{Manufacturing System Design}

A manufacturing system can be defined as the arrangement and operation of machines, tools, material, people and information to produce a value-added physical, informational or service product whose success and cost is characterized by measurable parameters (adapted from [4],[5],[6]). To integrate the many elements of a manufacturing system into a smoothly functioning whole is the challenge addressed by the manufacturing system design process. The word "design" is a very general term that is liberally used by many people both inside and outside of engineering. While the field of product design is still growing and is extremely dynamic, practitioners have a good understanding of what it means to design a product, although the methods and approaches are still debated. Some products can be very complex, but products typically have well-defined boundaries with clearly visible attributes that lead to performance characteristics that are readily discernible by the final user/customer. Manufacturing system design, on the other hand, elicits many different definitions and interpretations of the activities involved. Part of the reason for this difficulty is that manufacturing system design is multi-disciplinary and often involves many non-engineering fields. Another reason is that the notion of a manufacturing system is difficult to see let alone visualize in its entirety. Manufacturing system designs consist not only of physical hardware, but also of the people who manage and operate this hardware and who must communicate information within the manufacturing system as well as 
throughout the company's supply chain. One result of this broad scope is that it is very difficult to understand the interactions among the many details of a manufacturing system design.

In some cases, the focus of implementation is on simplified solutions and specific improvement tools (e.g. implementing kanban). This approach has often been the case in companies attempting to duplicate the success that Toyota has achieved with its production system ([7],[8]). Hayes and Pisano [9] note that companies trying to improve their competitiveness by implementing a program such as Just-in-Time (JIT) or Total Quality Management (TQM) seldom achieve the desired results, as they focus on these generic approaches rather than on developing their own unique competitive strategy. Shingo [10] describes other cases where improvement activities such as installing a kanban system fail because the necessary enabling practices, such as setup time reduction and defect prevention, have not been implemented.

In this paper, we define manufacturing system design as follows: manufacturing system design covers all aspects of creating and operating a manufacturing system. Creating the system includes equipment selection, physically arranging the equipment, work design (manual and automatic), standardization, design of material and information flow etc. Operation includes all aspects that are necessary to run the created factory.

\section{Research Objectives}

For a manufacturing system to satisfy the strategic objectives of a company requires that it be designed according to the following precepts:

1. Clearly separate objectives from the means of achievement

The clear separation of objectives and means allows designers to relate system details to the manufacturing system objectives. For example, manufacturing cells provide a means to satisfy numerous system objectives. However, implementing manufacturing cells without relating the use to system objectives may not lead to the desired outcome. The approach presented here allows the freedom to select among different physical implementation alternatives. The key point is to define and then achieve the desired set of objectives, regardless of the physical implementation.

2. Relate low-level activities and decisions to high-level goals and requirements

The system designers must be able to relate low-level decisions to the high-level system objectives. For example, equipment can greatly influence the way the manufacturing system is designed and 
operated [11]. Thus, it is necessary that the designers understand how the lower-level tactical design solutions achieve higher-level system design goals.

3. Understand the interrelationships among the different elements of a system design Lower-level decisions not only affect the achievement of higher-level goals, but the decisions also interrelate with other lower-levels decisions. For example, equipment selection influences the manmachine interface; changeover times affect possible run sizes. The manufacturing system design approach must provide a means to understand the interrelationships between design decisions to avoid local optimizations.

4. Effectively communicate this information across the organization

Unless there is a common mental map [12] and a common means to communicate objectives and means there can be no consistency in implementation within an organization. System designers need a road map or mental model of how to achieve the strategic objectives of a firm.

This research describes an approach to understanding the interactions among a diverse set of systemlevel requirements and to communicating this information throughout an organization. Though the concepts and applications of the MSDD have been presented in a number of prior publications, this is the first in-depth treatment of the MSDD's development.

After reviewing related conceptual approaches for thinking about manufacturing systems, this paper proposes a new approach, a manufacturing system design decomposition, for showing how an enterprise simultaneously achieves objectives such as cost, quality, delivery responsiveness to the customer, and flexibility. The decomposition starts with an overall objective of improving long-term return on investment (ROI). To improve ROI from a system design perspective requires a decomposition that relates the means (the physical implementation) to the objectives. Lower-levels of decomposition define the specific details of the manufacturing system design to achieve the higherorder objectives.

\section{Related Work}

Other approaches have been developed that guide people in making decisions about manufacturing system design by relating design decisions to important system characteristics such as operational costs. Hayes and Wheelwright [1] developed the well-known product-process matrix relating the structure of a manufacturing system to the volume and variety of the products it is to produce. Miltenburg [13] expanded upon this approach by comparing how layout, material flow, product 
volume and variety affected cost, quality, and flexibility in different high-level system designs (job shop, equipment-paced line, etc.). Approaches such as these can increase understanding of high-level system design choices at a conceptual level. However, these approaches fail to communicate how lower-level design decisions (such as equipment design, operator work content, etc.) will affect system performance. These approaches treat manufacturing system "design" as a problem of selecting an appropriate off-the-shelf design from a given set of choices and criteria. Designers are not given the freedom to create a unique manufacturing system to satisfy a broad set of requirements in a particular environment.

Some frameworks have been developed to trace low-level decisions to high-level system objectives. These frameworks often relate various manufacturing design and improvement "tools" to the objectives of a manufacturing organization. Gilgeous and Gilgeous [14] propose a framework that considers four high-level manufacturing system performance objectives (i.e. quality, cost, delivery, and flexibility) and eight tactical initiatives that each contribute to the achievement of each performance objective. Hopp and Spearman [3], beginning with the goal of "high profitability," developed a hierarchy of manufacturing objectives. This hierarchy, shown in Figure 1 demonstrates that "ideal" manufacturing system performance faces certain trade-offs. It also shows that one design element, short cycle time (throughput time), contributes positively both to cost reduction and increased customer service. These approaches do not state the means to achieve the given objectives, and do not provide a strong design link between strategic objectives and the operational means to achieve them.

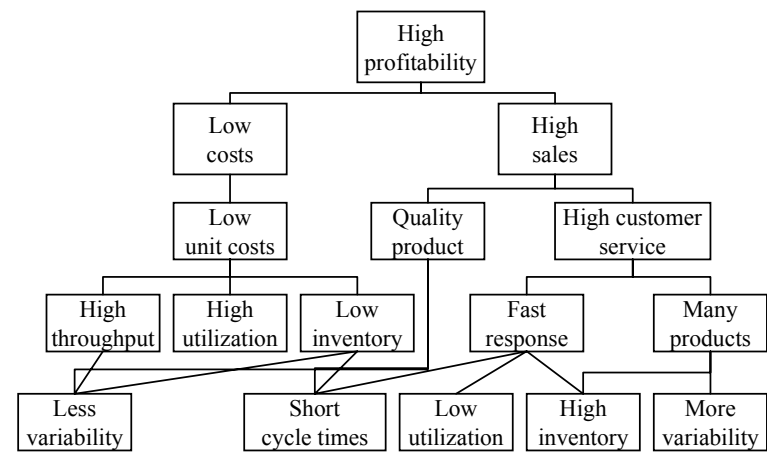

Figure 1: Hierarchy of manufacturing objectives [3]

Similarly, Monden [15]developed a framework (Figure 2) to show how the elements and improvement tools of the Toyota Production System (TPS) support high-level system objectives. The upward flow shown in Monden's figure describes the order in which these elements can be implemented, where the lower-level elements are viewed as being prerequisites. This type of framework is very useful in 
explaining why it is not enough to selectively copy aspects of TPS without first implementing others. However, Monden does not clearly distinguish objectives and means, but rather focuses on the physical tools (i.e. the means) of a pre-defined systems solution. This physically-focused framework makes it difficult to apply this approach in setting with different objectives.

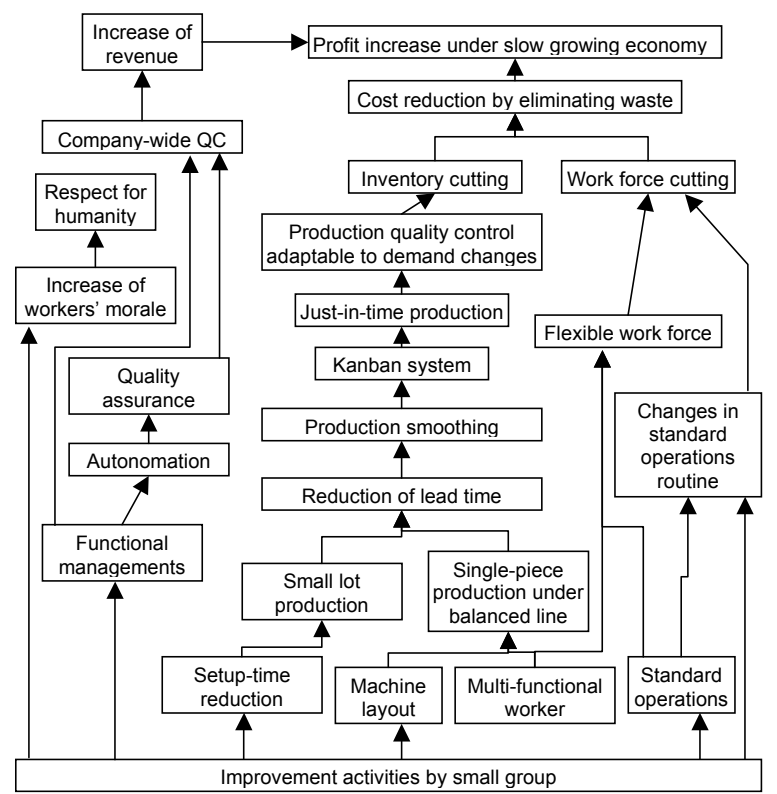

Figure 2: Relationships between goals and means [15]

Shop floor control is another important aspect of manufacturing systems. Melnyk defines shop floor control as a "subsystem of the entire manufacturing system" [16]. His shop floor control framework relates planning, control, and execution activities in a hierarchical manner. Spearman and Hopp developed a planning and control framework for pull production systems, which distinguishes strategic, tactical, and control aspects [3]. However, neither Melnyk nor Hopp and Spearman discuss the necessary design requirements on the shop floor for the successful implementation of their control frameworks. As a result, it is not clear how a system has to be designed to apply the developed control frameworks.

More recently, several authors have emphasized the need for better integration among various disciplines to create a comprehensive manufacturing system design [17] [18] [19]. Among these, Wu's [17] is the most comprehensive. The framework attempts to provide a unified approach to the design and operation of manufacturing and supply systems (Figure 3). The framework consists of three main areas, the three interfaces between the areas, and three layers of architecture that overlay all three 
areas. For example, $\mathrm{Wu}$ aims to delineate a clear link between the strategic positioning of a company (i.e. Manufacturing/Supply Strategy Analysis) and the best structure of a manufacturing system in order to support strategic objectives (i.e. Manufacturing/Supply Systems Design). The strengths of the approach (e.g. management/strategic perspective, unifying approach, link between strategy and manufacturing) are balanced by a weakness in defining a detailed design approach that defines objectives and the means to achieve them at every level of design - from strategy to operations.

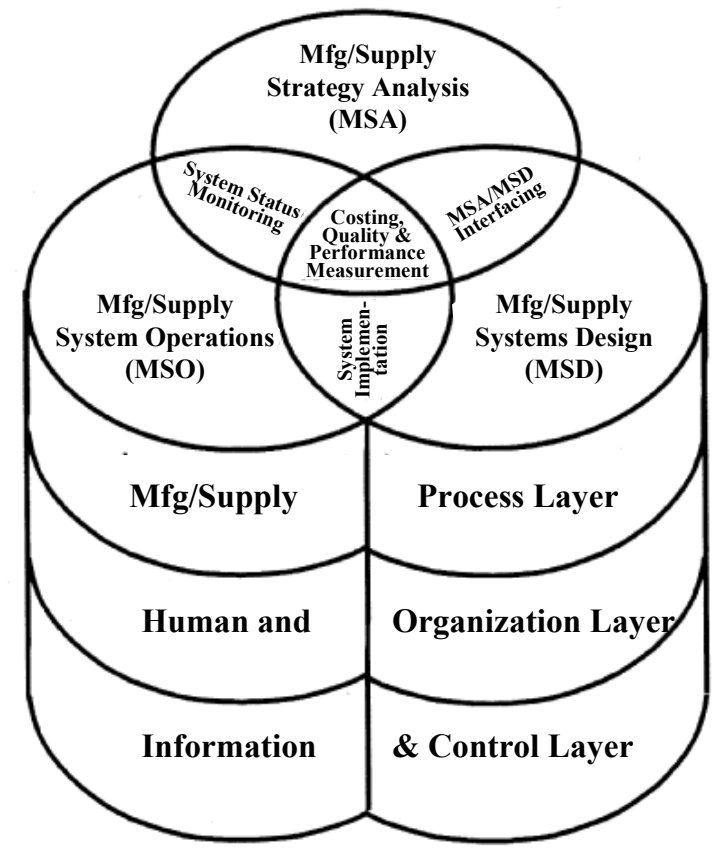

Figure 3: Structure of the Unified Manufacturing System Management [17]

In practice, manufacturing system design is characterized by a lack of formal design processes to link objectives and means. The numerous tools for manufacturing system design and control range from strategy frameworks (product-process-matrix) to manufacturing operations (pull planning framework). Most frameworks, however, do not recognize the separation of objectives and means throughout the entire detail of system design - from strategy to operations. These frameworks tend to state system objectives in strategic contexts and means in operational contexts, rather than providing a design approach that defines objectives and means achieve them at every level of detail. Others focus on a particular aspect of a manufacturing system without considering the overall system design. As a result, none of the frameworks can simultaneously satisfy the four stated research objectives. 


\section{Manufacturing System Design Decomposition}

As described previously, the motivation for developing the Manufacturing System Design Decomposition (MSDD) is the desire to have an approach, which can satisfy the four stated research objectives. The focus of the decomposition is on specific activities and decisions that are likely to be under the control or influence of the group of engineers, managers, and operators responsible for designing and running a manufacturing system. Thus, the decomposition is limited to the shop floorlevel.

Concepts and ideas included in the decomposition came from a variety of sources, including the literature on manufacturing system design, studies of the Toyota Production System, and the previously described frameworks. Several research projects with industrial partners involving the design of actual manufacturing systems were also valuable sources of information. These projects include work in a variety of industries, including automotive, consumer goods, aircraft, and food processing, as it was desired that the decomposition be general enough to apply to a wide range of industries and competitive environments. Previous versions of the design decomposition are examined by ([6],[20],[21],[22],[23]).

The axiomatic design methodology was used to develop the MSDD [24]. The fundamental concepts of axiomatic design will be presented, followed by a detailed description of the MSDD.

\section{Axiomatic Design}

Axiomatic design was developed in order to provide a structured, scientific approach for the generation and selection of good design solutions [24]. While there are many steps in the engineering design process, the axiomatic design process focuses on the generation of requirements and the selection of means for achievement. In fact, one of the central ideas of axiomatic design is the importance of distinguishing between what (objectives) is to be achieved and how (means) it will be achieved. In axiomatic design terminology, the objectives of the design are expressed as Functional Requirements (FR's) and the solutions are expressed as Design Parameters (DP's). The design process is one of selecting the best set of DP's to satisfy the determined FR's.

\section{AD Process}

The axiomatic design methodology begins with the identification of customer needs and the conversion of these needs into a set of one or more high-level functional requirements. The goal is to 
develop the minimum set of independently achieved requirements that completely characterize the desired functions of the design [24]. Suh describes achieving this result as a process of first mapping from the customer domain to the functional domain to state (objectives) functional requirements (FR's) in solution-neutral terms. Next, the designers must determine how the just-determined FR's will be met by the (means) design parameters (DP's). Synthesis of design parameters is essentially a creative process. At high levels, the DP's may be conceptual in nature and may describe a general system or structure for achieving an FR without yet containing enough information to be implemented. At lower levels of decomposition, DP's typically describe a physical solution in enough detail for a concept to be implemented. Typically, decomposition proceeds until all FR's and DP's have been decomposed to an operational level of detail.

In axiomatic design, the FR's and DP's are connected by means of design matrices. That is, a vector of FR's can be related to its associated vector of DP's according to the equation:

$$
\left\{\mathrm{FR}^{\prime} \mathrm{s}\right\}=[\mathrm{A}]\left\{\mathrm{DP}{ }^{\prime} \mathrm{s}\right\}
$$

The elements of the design matrix, A, indicate the affects of changes of the DP's on the FR's [25]. As an example, consider the design equation shown below:

$$
\left\{\begin{array}{l}
F R_{1} \\
F R_{2} \\
F R_{3}
\end{array}\right\}=\left[\begin{array}{ccc}
X & 0 & 0 \\
X & X & 0 \\
X & 0 & X
\end{array}\right]\left\{\begin{array}{l}
D P_{1} \\
D P_{2} \\
D P_{3}
\end{array}\right\}
$$

The binary elements of the design matrix, expressed as X's and 0's, indicate the presence or absence of a relationship between a DP and the associated FR. X's should always be present along the diagonal, meaning that each DP affects its associated FR (e.g., $\mathrm{A}_{11}=\mathrm{X}$ indicates that $\mathrm{DP}_{1}$ affects $\mathrm{FR}_{1}$ ). The $\mathrm{X}$ at $\mathrm{A}_{21}$ shows that $\mathrm{DP}_{1}$ also affects $\mathrm{FR}_{2}$. This design matrix information can also be represented graphically. An arrow from a DP to an FR indicates the presence of a non-zero, off-diagonal element in the design matrix. For example, Figure 4 provides the graphical representation of the design matrix shown in equation 2. 


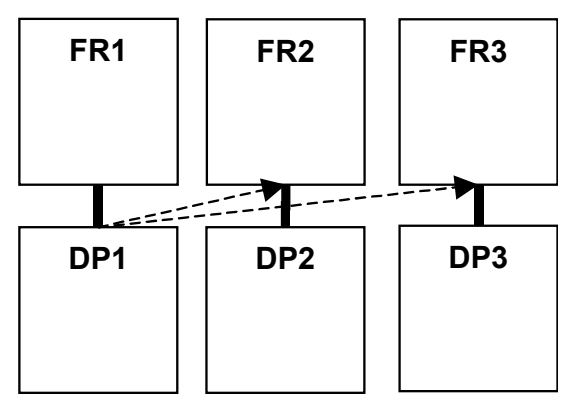

Figure 4: Graphical representation of design matrix of equation (2). An arrow from a DP to a FR indicates the presence of a non-zero off diagonal element in the design matrix.

The relationships between the FR's and DP's in the MSDD are more conceptual in nature and the following questions were used to determine the appropriate value for an element $\mathrm{A}_{\mathrm{ij}}$ of a design matrix: Does the particular choice of $\mathrm{DP}_{\mathrm{j}}$ affect system performance in terms of $\mathrm{FR}_{\mathrm{i}}$ ? Would failing to implement $\mathrm{DP}_{\mathrm{j}}$ impede the manufacturing system's ability to satisfy $\mathrm{FR}_{\mathrm{i}}$ ? These questions were developed to formalize the process for filling in the entries of the design matrix and to describe the thinking that goes into the determination of each entry.

\section{Selection of the best set of DP's}

The two axioms of axiomatic design are used to select the best set of possible design parameters. The two axioms are as follows [24]:

1. The independence axiom: Maintain the independence of the functional requirements.

2. The information axiom: Minimize the information content of the design

The first axiom states that when multiple FR's exist, the design solution must be such that each FR can be satisfied without affecting the other FR's. When this objective is achieved, the design matrix will be diagonal, as each DP will affect only its associated FR with no coupling occurring in the off-diagonal elements. Such a design is said to be uncoupled. In cases where independence is not achieved, two possibilities arise. In one case, the design will be partially coupled, meaning that the rows and columns of the design matrix can be interchanged such that the matrix is upper or lower triangular. When offdiagonal elements exist and the matrix cannot be rearranged to a triangular state, the design is said to be coupled. An acceptable design is either uncoupled or partially coupled. A partially coupled design is said to be path dependent. 
The information axiom states simply that simpler designs are better. Quantifying the complexity or information content of system designs can be quite challenging, however. The information axiom was not used in creating the MSDD and thus will not be discussed further herein.

The two axioms can be used to select the best possible set of DP's when multiple options have been developed. Ideally, one would like to find a set of DP's that maintains functional independence (i.e., avoids coupling) while maintaining minimal complexity. These two goals are generally found to be consistent, as the presence of non-zero, off-diagonal elements in the design matrix leads to complexity in system designs.

Once a set of DP's has been determined, the next step is to decide if further decomposition is necessary. In the case of the MSDD, decomposition proceeds for as long as it is possible to do so without limiting the usefulness or range of applicability of the decomposition. When further decomposition is needed, the next step is to develop the next level of FR's. By following a downward path in the MSDD (shown in Appendix A), one can see this alternation back and forth between FR's and DP's.

In developing lower-level FR's for the MSDD, the focus was on breaking down the higher-level FRDP pairs into component parts. Questions asked at this stage included: What are the components of the parent FR and/or DP? What requirements are placed on these components?

Reading from left to right, the MSDD indicates path dependence. The FR-DP pairs on each level are arranged in such a way that the pair whose DP influences the most FR's is on the left side. We see that quality, then problem resolution, then predictable output, then throughput time reduction, then labor reduction are critical to implementing the desired system-design goals (see Figure 7). As a result, decisions should be made following the MSDD from left to right. A summary of the axiomatic design process for decomposition is shown in Figure 5. 


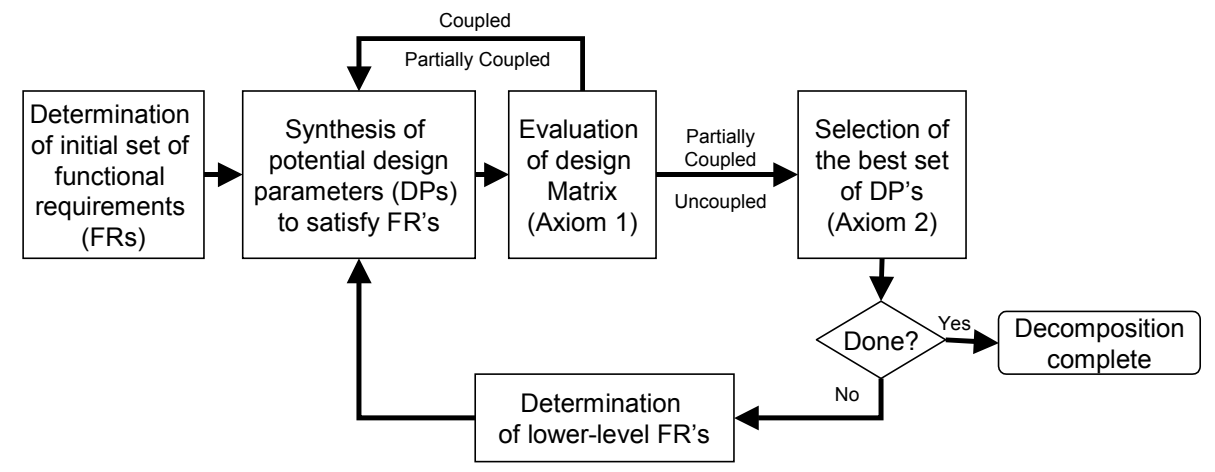

Figure 5: Simplified axiomatic design decomposition process

It was found that the strengths of axiomatic design, namely the emphasis on separating the objectives (the FR's) from the means (DP's) and the structured decomposition process, made it particularly well suited to achieve the proposed research objectives. Other design methods such as Quality Function Deployment [26] and $\mathrm{IDEF}_{0}$ [27] provide more structure for other phases of the design process such as capturing customer needs or creating a complete functional model of a system, but provide less guidance for the decomposition of requirements and design parameters, which is the focus of this research. For more detail on the axiomatic design methodology, the reader is directed to the work of [24],[25].

\section{The Manufacturing System Design Decomposition (MSDD)}

The complete version of the MSDD is shown in Appendix A. The MSDD currently defines the foremost requirement of any manufacturing system to "Maximize long-term return on investment." In this context, long-term return on investment (ROI) refers to the life cycle of a given system, and not just in the immediate future.

ROI has often been criticized as a measure of performance based on the claim that it encourages shortterm thinking at the expense of long-term improvements [28],[29]. The view taken here is that ROI does not inherently cause this behavior, it is the means often used to estimate ROI that results in a focus on the short-term. That is, the benefits of making advances such as reducing inventory, developing new products, creating a flexible system, improving customer relations, etc. can be very difficult to quantify in financial terms, and so these benefits are often ignored in the calculation of the return on investment for a potential project. Although long-term ROI may be very difficult to predict accurately, ROI is taken here as the highest-level focus of the manufacturing function as it represents a 
general objective that is applicable to a wide variety of manufacturing environments and is not inherently contradictory to any accepted improvement activities.

The design parameter chosen as the means to achieve FR-1 is DP-1, "manufacturing system design." Although other parts of a firm certainly contribute to overall performance and ROI, the focus of this work is the design of manufacturing systems. The decomposition will be limited to those factors that a system design team has the ability to strongly influence or control. FR's at the next lower level were determined based on the components of ROI as given by:

$$
R O I=\frac{\text { Revenue }- \text { Cost }}{\text { Investment }}
$$

The manufacturing system design solution (DP-1) was then decomposed into three sub-requirements: maximize sales revenue, minimize production costs, and minimize investment over the production system life cycle. Accordingly, DPs are selected to satisfy the given Functional Requirements and the Independence Axiom (Figure 6). Each of these three DPs is then decomposed into FRs and DPs at the next lower level.

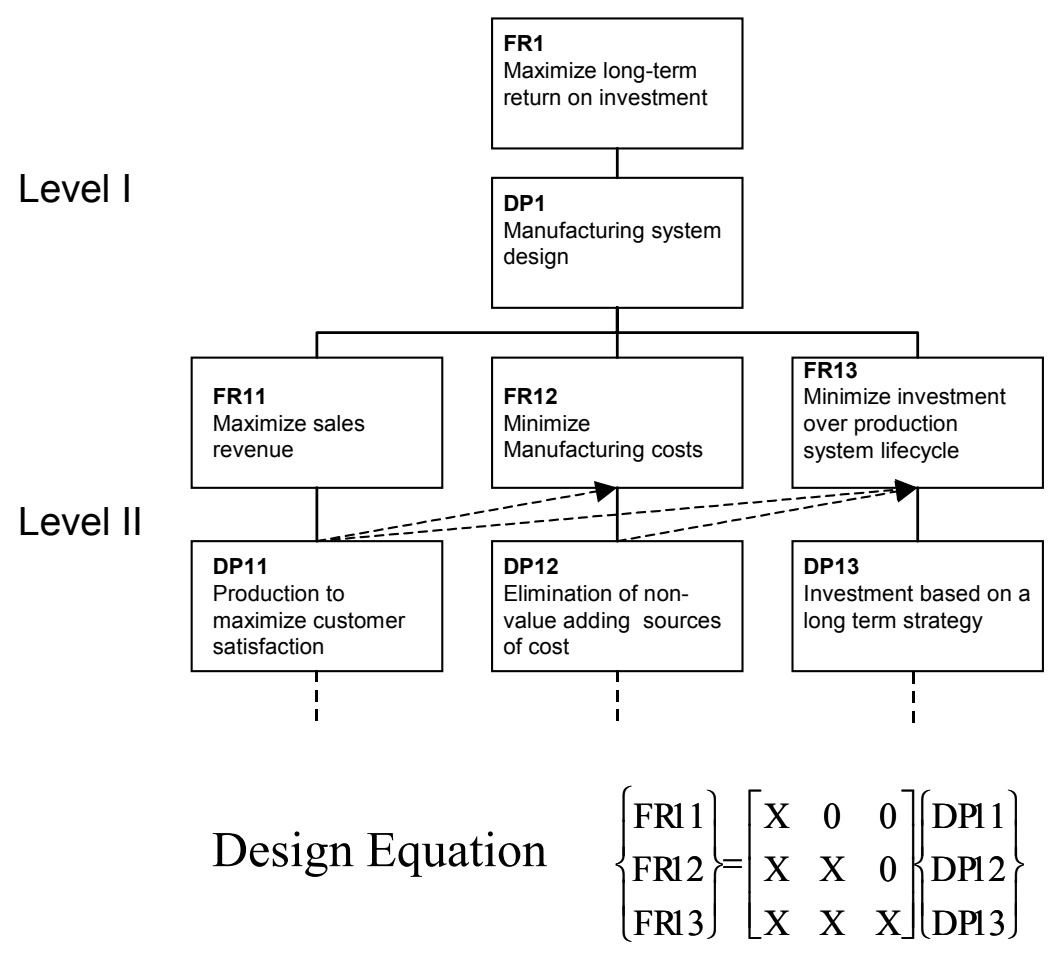

Figure 6: The first 2 of 6 levels of the MSDD

As a path-dependent (i.e. partially coupled) design, the MSDD treats customer satisfaction (DP-11) as a prerequisite for the rest of the decomposition, meaning that it is a goal that must be achieved before 
costs and/or investment can be minimized. The MSDD interrelationships show clearly that minimizing running costs and investment at the expense of customer satisfaction is not a valid means for achieving the highest-level goals of the system design. This information is consistent with related empirical and theoretical work in the literature. Ferdows and De Meyer [29] developed a "sand cone" model, describing that manufacturing capabilities should be built by starting with quality, then focusing on dependability, then reaction speed and flexibility, and finally focusing on cost efficiency. Fillippini et al. [30] present empirical evidence to examine the existence of tradeoffs among different aspects of manufacturing performance, finding that compatibility between delivery punctuality and economic performance was only observed in situations where high values of quality consistency had been achieved.

The detail of the MSDD can be simplified, as shown in Figure 7. By the fourth level of decomposition, the FR-DP pairs are organized into six different branches. The underlying principles of all the branches are briefly described in the following pages. In addition, an in-depth discussion of two particular branches of the MSDD - the Identifying \& Resolving Problems, and Predictable Output Branches - are described. These two branches are particularly unique to the development of the MSDD as they represent the design of system feedback (i.e. Problem Solving) and system stability (i.e. Predictable Output). As will be described, these two branches focus upon minimizing the variation (i.e. $\sigma_{\mathrm{X}}$ ) in the manufacturing system design.

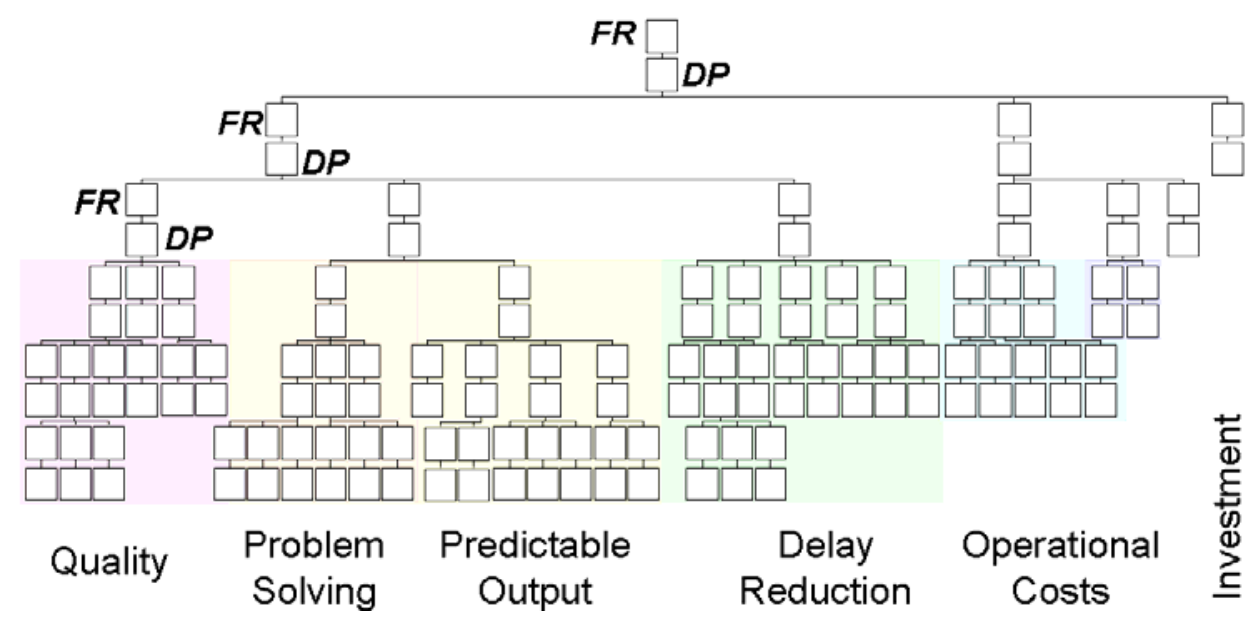

Figure 7: The MSDD's different Branches

Maximizing customer satisfaction (DP-11) was selected as the means to maximize revenues (Figure 8). This DP was then further decomposed based on the key attributes of manufacturing system performance that affect customer satisfaction: conformance quality (FR-111), on-time delivery (FR- 
112), and minimal lead-time (FR-113). The prescribed means for achieving high quality is to ensure that production processes have minimal variation from the target (DP-111). DP-111 is focused on improving processes rather than trying to use final inspection to prevent the shipment of bad parts. The design matrix at this level (shown graphically with arrows in Figure 8) shows that achieving conformance quality (DP-111) is critical for improving customer satisfaction. Quality variation and the production of defects makes system output unpredictable, which adversely affects FR-112, "Deliver products on time," and means that more parts will have to be produced to replace these defects, adversely affecting FR-113, "Meet customer expected lead time." High conformance quality is a critical factor required to reduce the affect of DP-111 on the predictable delivery and lead time of a manufacturing system design.

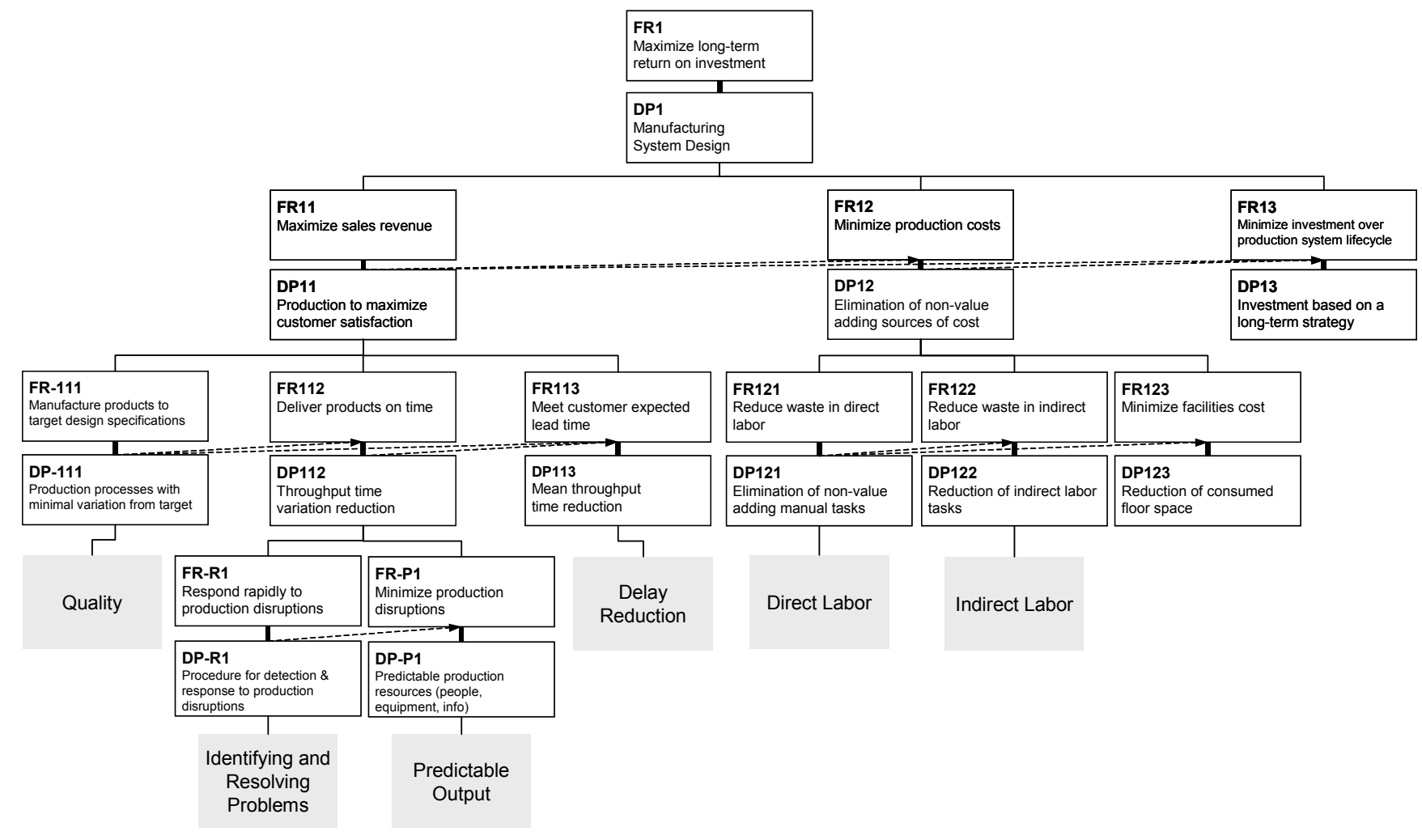

Figure 8: Upper levels of the MSDD

On-time delivery (FR-112) and short lead-time (FR-113) are achieved by reducing the variation, $\sigma_{\bar{x}}$, and the mean, $\bar{x}$, manufacturing throughput time (described by DP-112 and DP-113, respectively, as shown in Figure 9). Variation reduction requires the ability to respond rapidly to production disruptions when disruptions occur, which is designated by the branch R1, and the increase of the reliability of production resources, designated by the branch $\mathrm{P} 1$. 


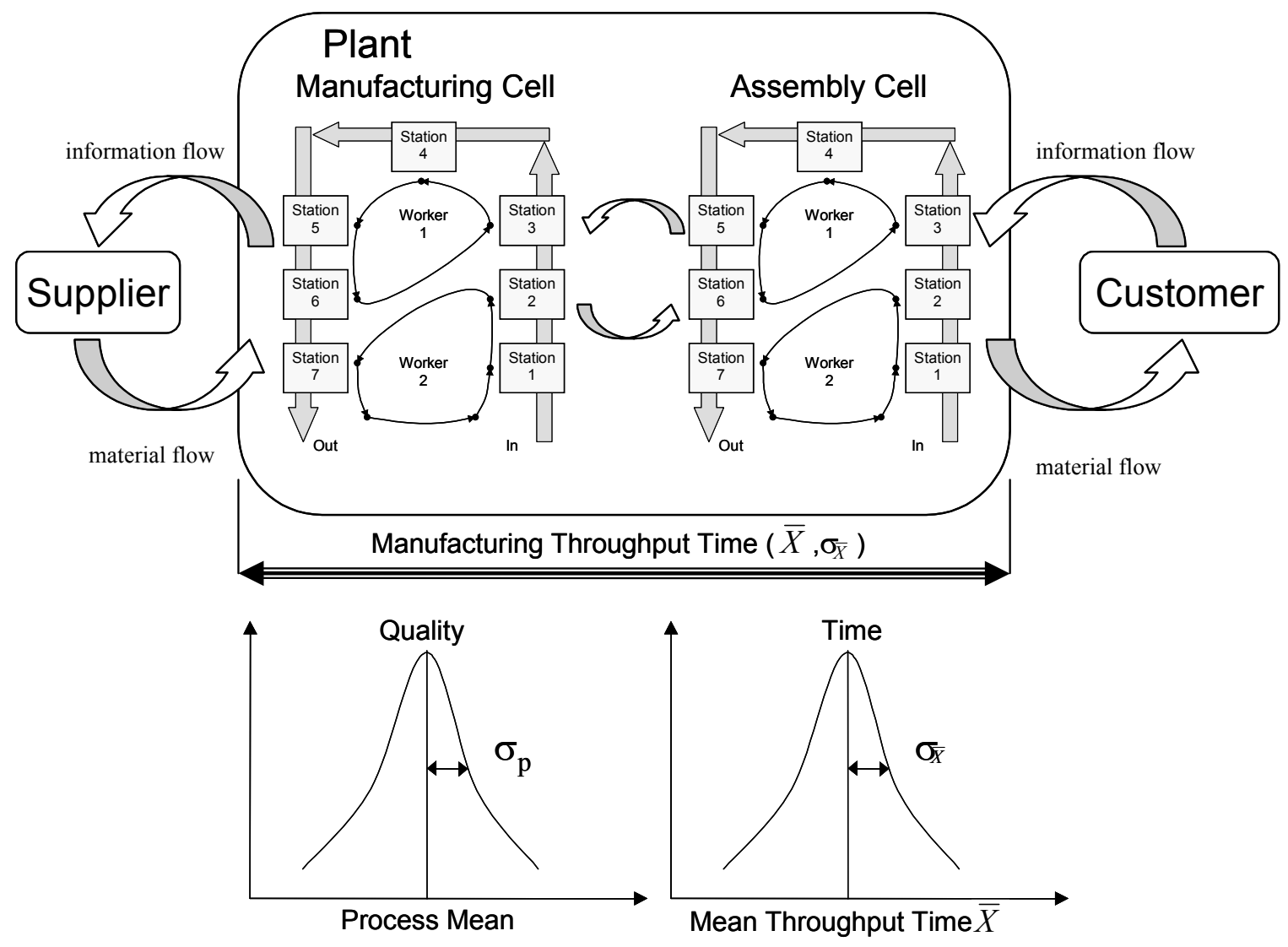

Figure 9: The flow of parts through a linked cellular manufacturing system.

Mean throughput time reduction is decomposed based on the various causes of delays in manufacturing systems (FR's T1-T5). It is important to note the distinction made here between causes of variation in throughput time (addressed by DP-112) and causes of increases in mean throughput time (addressed by DP-113). The decomposition of DP-112 focuses on the elimination of factors that cause variation in the predicted system output time; decomposition of DP-113 focuses on factors that increase throughput time but that can be accurately predicted. Likewise, the process quality branch isolates factors that affect process variation in terms of the mean and variation. Figure 9 illustrates this concept, showing the parallel between the mean and variation in quality and the mean and variation in throughput time. In a hypothetical system in which no variation in quality or time exists, each order's delivery time can be determined in advance to ensure that the mean on-time delivery performance is satisfied.

The rightmost portion of the decomposition deals with reducing production and investment costs. Elimination of non-value adding sources of cost (DP-12) is the means for reducing production costs (FR-12). Three sources of waste are considered: direct labor (FR-DP 121), indirect labor (FR-DP 122), 
and facilities (FR-DP 123). Note that other "wastes" in manufacturing systems such as storage, transportation, and overproduction have already been considered in the decomposition as they increase throughput time as well as cost. Decomposition of DP-121 and DP-122 focuses on the effective utilization of labor, rather than on elimination of labor content and headcount reductions.

Finally, FR-13, minimizing investment over the system life cycle, is achieved by making investments based on a long-term system strategy. No further decomposition of this FR-DP pair is presented in the MSDD, as the specifics were found to be too dependent on the particular application. Decisions here might affect, for example, how flexible the system will be to changes in production volumes, or to changes in product design, or to the variety and mix of products demanded. There is no general answer as to how much flexibility is "the right amount," instead, the desired flexibility must be evaluated based on the firm's competitive environment and desired niche in the market.

\section{Throughput time variation reduction - Identifying \& Resolving Problems \& Predictable Output}

On-time delivery of products (FR-112) is dependent on the reduction of variation in throughput time. Throughput time variation is largely a consequence of the degree of disruptions in the manufacturing system as well as how these disruptions are resolved. Disruptions as indicated by the MSDD are problems that lead to a loss in system availability. Quality problems, though disruptive to a manufacturing system, are treated separately under the previously described FR-111 "Manufacture products to target design specifications" branch and therefore the decomposition of DP-112 (Throughput time variation reduction) considers only disruptions that do not result from quality problems.

Decreasing the variation of delivery time to the customer requires a manufacturing system to have predictable output. With greater predictability, a company can make promises to its customers with the confidence and assurance that it can meet promised delivery times. When customers consistently receive products in the same amount of time from one order to the next, they are likely to gain confidence in the ability of the manufacturer to satisfy their orders. The result is a strengthened business relationship.

The requirement to produce with a predictable time output reflects a manufacturing system's ability to decrease variation in delivery time. Producing in a consistent and timely manner can be done when production resources are reliable and in themselves predictable. The resources that affect timely production are having sufficient material supply, adequate machine availability, and consistent labor 
productivity. The ability to resolve production disruptions (DP-R1) is a prerequisite for minimizing production disruptions. Thus, the design matrix for the decomposition expresses a partially coupled design as shown in Figure 10.

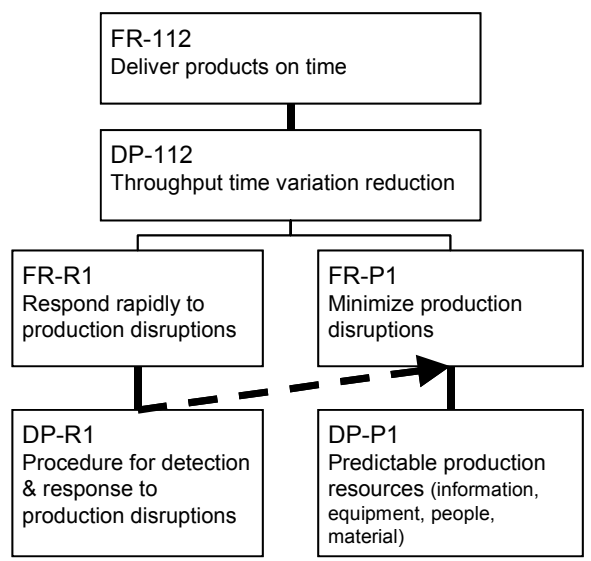

Figure 10: Reduction of throughput time variation consists of two parts: respond rapidly to disruptions and ensuring predictable resources.

\section{Identifying \& Resolving Problems Branch}

Identifying and resolving problems relates to throughput time variation caused by unplanned production disruptions. Any manufacturing system experiences disruptions and must be able to solve them. This section discusses the decomposition of FR-R1 "Respond rapidly to production disruptions" and its corresponding DP-R1 "Procedure for detection and response to production disruptions" as shown in Figure 11. The main goal of the decomposition branch is to achieve a manufacturing system that can be improved by being able to recognize and eliminate weaknesses In order to accomplish DPR1, disruptions must be recognized (FR-R11), communicated to the right resource (FR-R12), and eventually be solved (FR-R13). The associated DP's are conceptual and refer to disruption detection enabling system configurations (DP-R11), feedback procedures (DP-R12), and standard improvement methods (DP-R13). The dependencies follow the logic that disruptions must first be recognized, then communicated and then resolved.

The underlying thinking of the decomposition of DP-R11 is that the system configuration (design and operation) enables the operator in recognizing disruptions (when, where and what). Technology can be a great help in achieving these goals by providing instantaneous feedback about the state of the manufacturing system. However, the perspective taken here is that the operator is the ultimate source of dealing with disruptions, which is expressed in the wording of DP-R11 and DP-R12. 


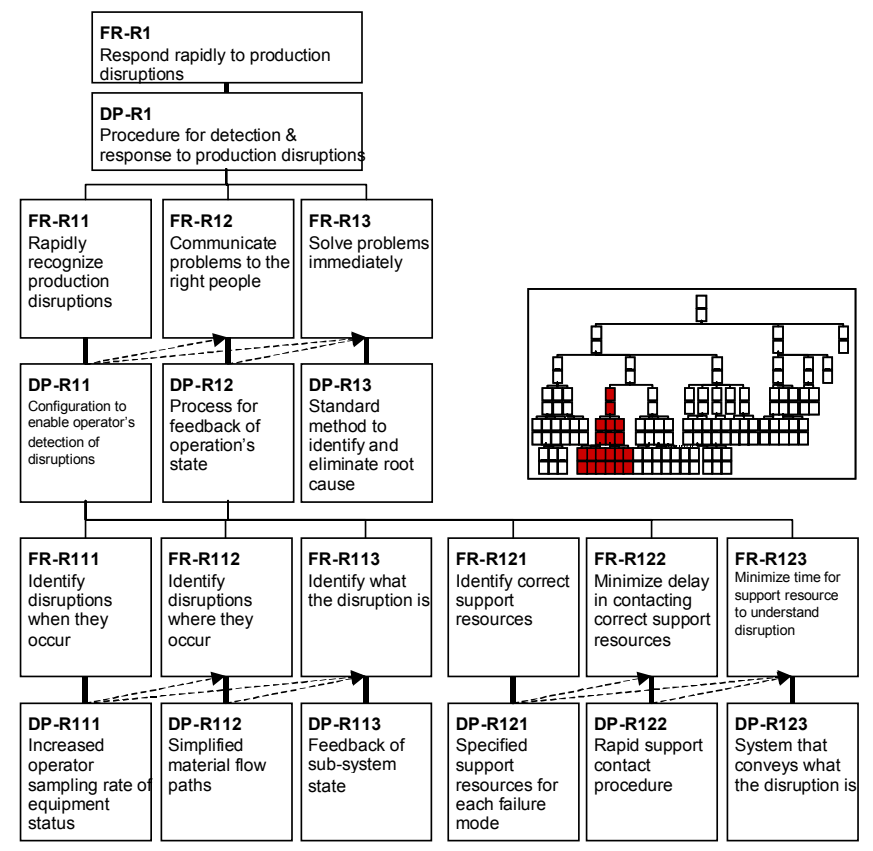

Figure 11: Identifying and resolving problems branch of the MSDD

\section{Predictable Output Branch}

Rapidly responding to and resolving of production disruptions creates the basis to eliminate production disruptions. To minimize production disruptions (FR-P1), predictable production resources are required (DP-P1). Four types of production resources must be predictable: information (FR-P11), operator (FR-P12), equipment (FR-P13), and material (FR-P14), as shown in Figure 12. 


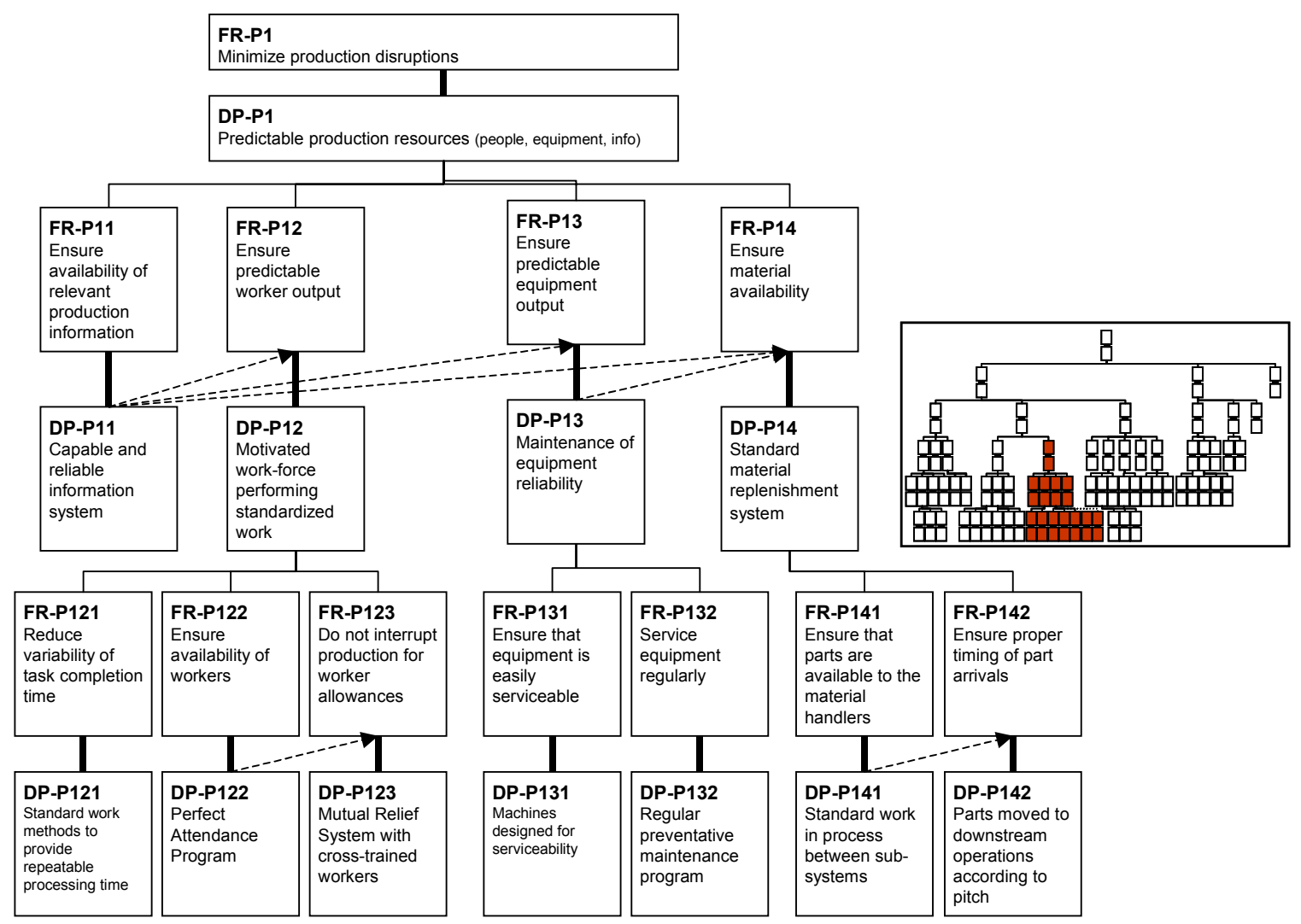

Figure 12: The decomposition of predictable resources distinguishes information, equipment, people, and material.

Figure 12 highlights the importance of a capable and reliable information system (FR-P11). An information system allows the gathering and storing of data, its transformation into information, and the transfer of information from sender to receiver. Thus, the information system supports the achievement of predictable output from all resources of the manufacturing system by providing timely, reliable, and relevant information.

There are numerous norms and guidelines for the design of work systems from ergonomic to psychological aspects to achieve stable operator output (FR-P12) (e.g. [31],[32]). Quality and cost aspects of standard work procedures are covered by DP-Q122 for stable quality output and by the decomposition of the direct labor branch (DP-D1). Three requirements are defined to achieve stable time output from operators as shown in Figure 12: reducing variation of task completion time (FRP121) by defining standard work methods (DP-P121); ensuring that operators are available when tasks need to be performed (FR-P122); and avoiding production disruptions due to worker allowances (FRP123) by mutual relief (DP-P123). Cross training also increases operators' competence and flexibility and helps to improve quality and reduce costs. 
The decomposition of FR-P13, "Ensure predictable equipment output," and its corresponding DP stresses that equipment must be designed for serviceability (FR-P131) to achieve successful maintenance (FR-P132). Further details about equipment maintenance can be found in the literature of total productive maintenance (e.g. [33])

The predictability of equipment output influences the availability and delivery of material. Thus, DPP13 affects FR-P14 "Ensure material availability" (see arrow between DP-P13 and FR-P14 in Error!

Reference source not found.). FR-P14 requires parts to be available when demanded (FR-P141) and to ensure proper timing of part arrival at downstream processes (FR-P142). Standard Work In Process (SWIP) between subsystems (DP-P141) serves as a buffer against production uncertainties and transportation delays. Low volume manufacturing may require a different strategy to ensure part availability, since it might not be possible to keep standard amounts of material between the manufacturing processes.

\section{Integration of MSDD}

The MSDD provides an excellent platform to integrate the various disciplines of manufacturing system design. Existing frameworks for each discipline could be linked through the MSDD as illustrated in Figure 13.

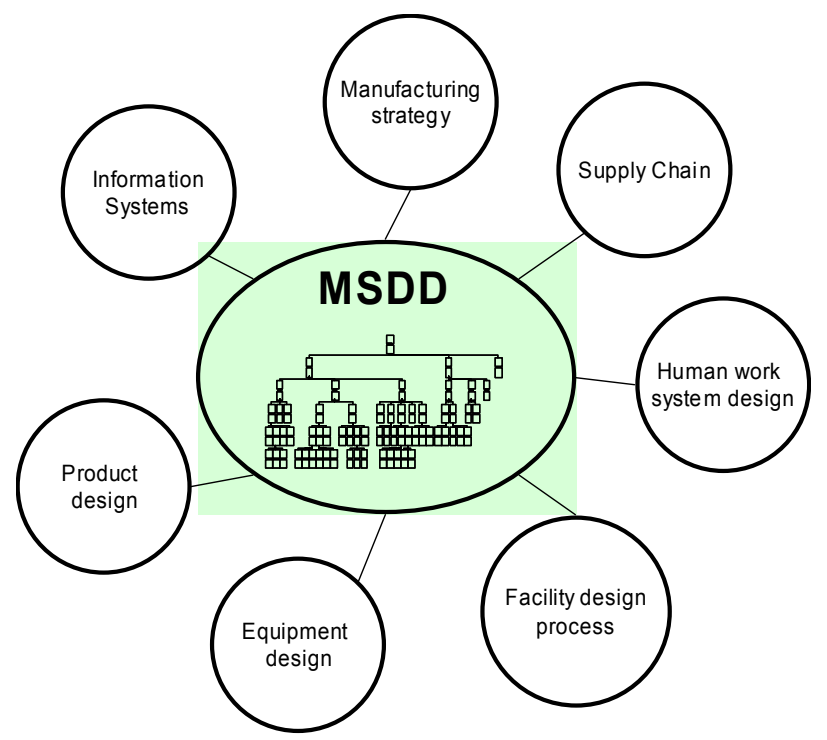

Figure 13: MSDD relative to various disciplines of manufacturing system design. 
Duda [34] developed a process for linking manufacturing strategy with the MSDD. The process guides the designer from stating strategic objectives through performing trade-off analysis of design alternatives relative to the objectives, to evaluating the relative strength of design alternatives. Arinez [35] laid out an equipment design approach that uses the MSDD as a source of equipment design requirements. The approach is comprised of four main steps: identification of the set of manufacturing system requirements that affect equipment design, transformation of the requirements into views for the various types of equipment designers, analysis of requirements, and decomposition of the requirements into equipment design parameters.

Cochran et al. developed a process how the MSDD can be used for facility design [36]. The MSDD is combined with a procedural system design approach as proposed by [37]. The MSDD defines the design objectives, which become the input for the design phases of the procedural approach. The general procedure of linking the two approaches is shown in Figure 14.

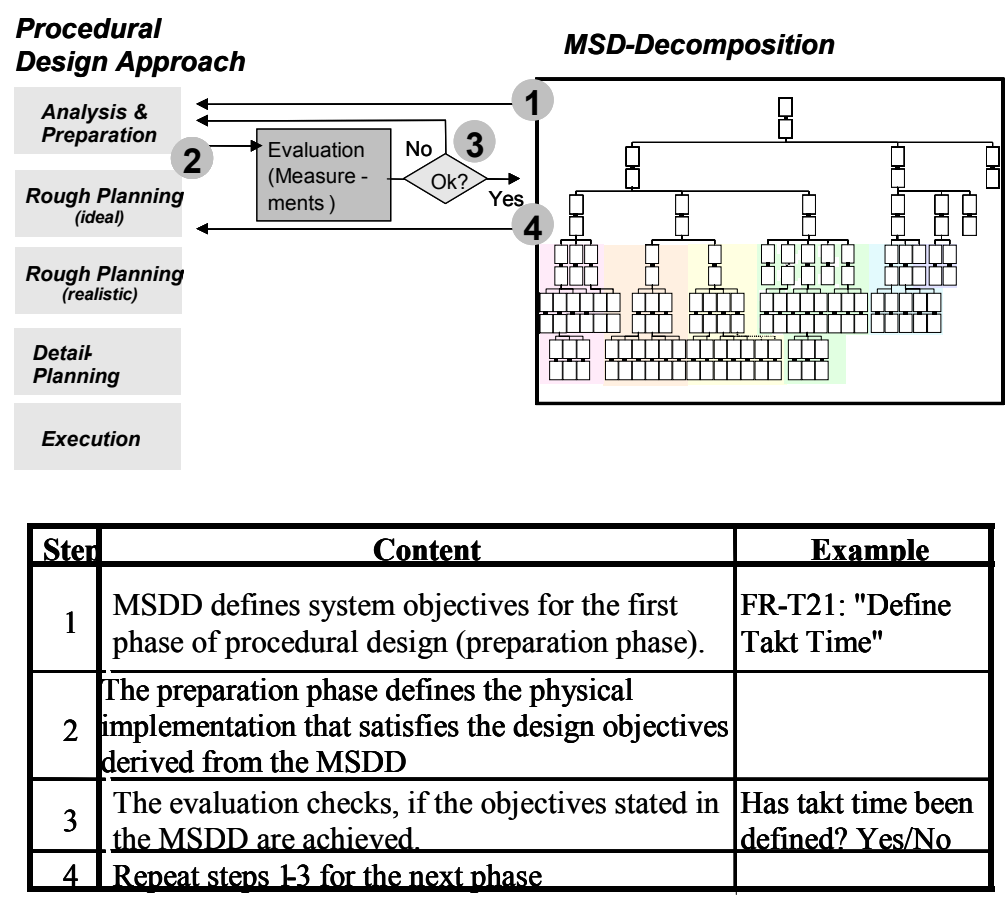

Figure 14: Combination of procedural design approach with MSDD. (Cochran et al., 2000b)

The benefit of integrating the MSDD with a top-down procedural manufacturing system engineering approach is the ability to communicate manufacturing system design requirements and dependencies during each phase of the design process. The top-down approach guides the physical design decisions, while the MSDD is used to ensure that the system design achieves the stated objectives. The 
combination of both approaches greatly enhances the effectiveness of manufacturing system design projects.

\section{Applications}

\section{Illustrative example}

The following example illustrates how the MSDD can be used to illustrate why optimizing the cost of an operation can negatively impact the achievement of the goals of a manufacturing system as a whole. In this example, one high-speed draw furnace costs less at an equivalent capacity than eleven induction tempering machines. The operation-focused decision would lead to the purchase of the lower cost machine regardless of the impact of this purchase on the manufacturing system as a whole.

Let us consider the equipment selection for tempering steering gear racks with two different machine concepts. Concept one is to use a large draw furnace capable of processing the aggregated demand from customer operations in the departmental plant. This machine is a "process island." The throughput time is $1 \frac{1}{2}$ hours. Its cycle time is 5 seconds. Parts flow continuously through the machine on conveyors. The second concept uses an induction tempering process. The machine is narrow and is a single cycle automatic machine. The machine processes a part every 54 seconds at the same pace of its customer assembly cell.

Eleven machines would have to be purchased to have the same capacity as the draw furnace. Assume that each machine is equally capable of producing parts to the desired specifications. Figure 15 shows a sketch and additional information of both machines.
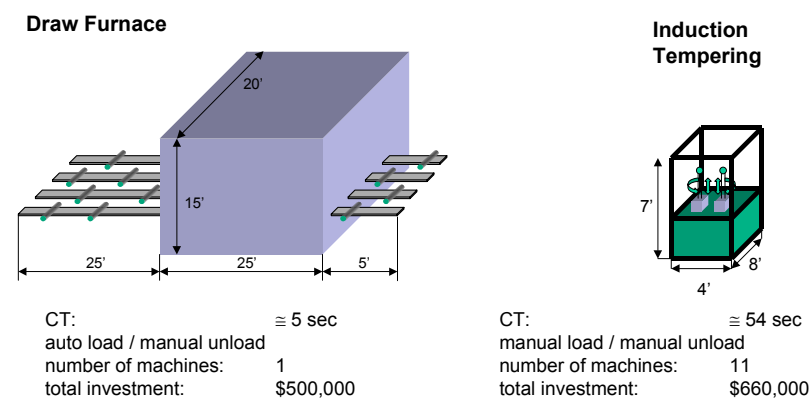

Figure 15: Two different equipment concepts

The MSDD illustrates the impact of the different equipment concepts relative to the manufacturing system design. The draw furnace has a very short cycle time and is fed by multiple upstream machines. Thus, it becomes difficult to identify disruptions where they occur (FR-R112), which in turn may lead 
to hiding disruptions (if one machine of the multiple machines at the upstream process fails, the loss in production capacity does not require an immediate response and may go unnoted). As a consequence, throughput time variation reduction (DP-112) is difficult to achieve (see leftmost arrow in Figure 16).

The cycle time of the draw furnace is five seconds, which makes it very hard to balance the system (FR-T221) causing process delay (FR-T2). The size of the draw furnace also hinders the ability to establish a material flow oriented layout to reduce transportation delay (FR-T4). Both effects will eventually increase throughput time (FR-113), which is represented by the middle two arrows in Figure 16.

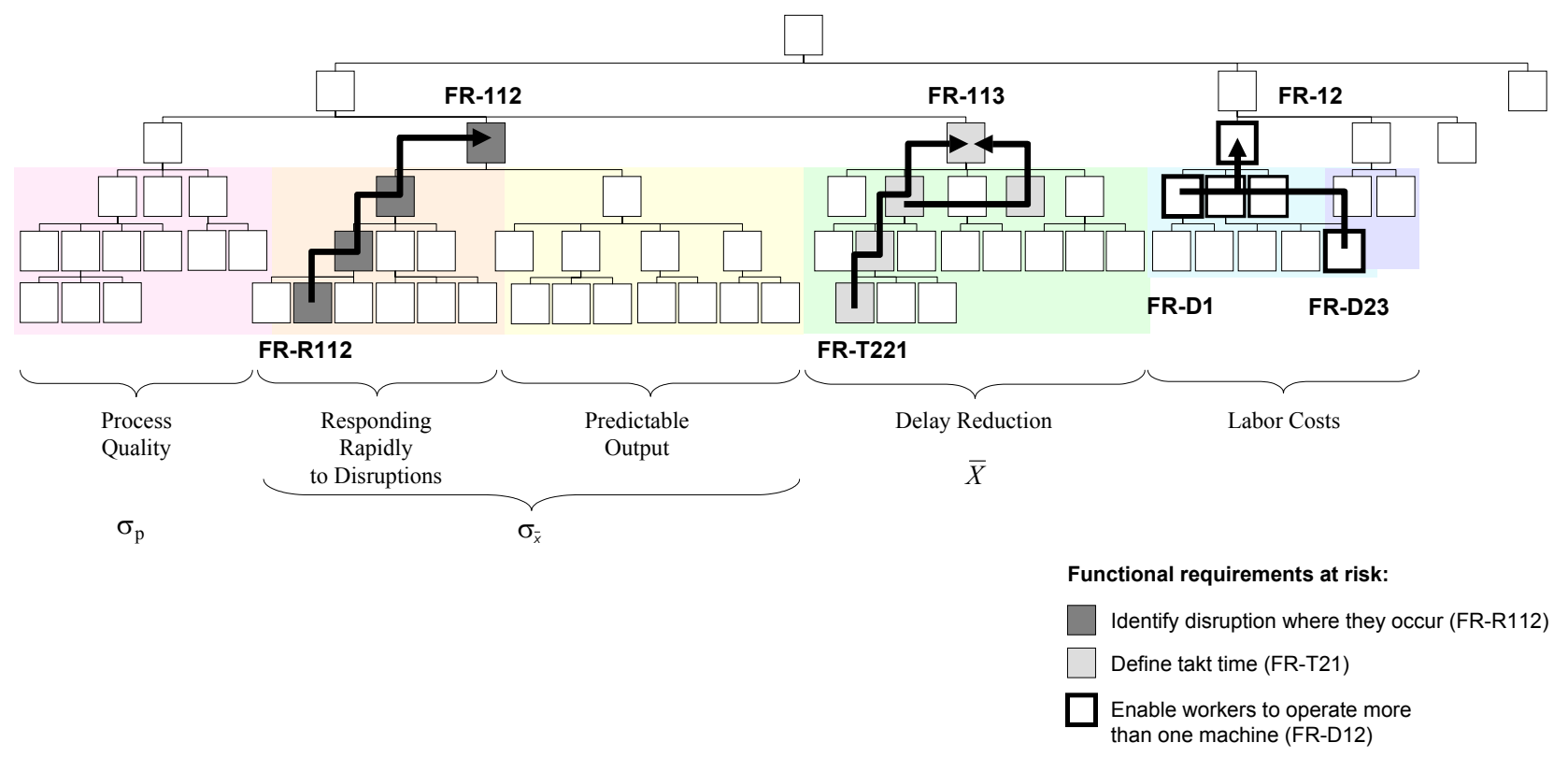

Figure 16: Impact of the draw furnace in achieving high-level system objectives. The design of the draw furnace (DP) makes it difficult to satisfy the marked low-level FR's. The arrows illustrate, which high-level system objectives are at risk to be satisfied

The draw furnace also has ergonomic weaknesses (rightmost arrow in Figure 16). The cycle time of 5 seconds prevents man-machine separation (FR-D1) and the size of the machine requires a lot of walking (FR-D23). Figure 16 summarizes the discussed relationships. The induction-tempering machine would avoid the stated problems. The machine could be integrated into a manufacturing cell to achieve simplified material flow paths (FR-R112), to balance the system (FR-T221), to reduce unnecessary walking (FR-D23), and to allow the operator to operate multiple machines (FR-D1). 
However, an operation-focused decision as driven by traditional management accounting does favor the draw furnace. The management accounting emphasizes the reduction of the unit cost of the tempering operation [38]. The MSDD shows clearly the error in the unit cost equation logic. The unit cost equation stresses direct labor reduction at the expense of other objectives. Direct labor reduction is the fifth tier to achieving the manufacturing system objectives as indicated by the MSDD. Quality, then problem solving, then reliability, then throughput time reduction, and then labor cost must be emphasized. The discussed example illustrates the importance of understanding the interrelationships of the manufacturing system with a comprehensive view, instead of a narrow, operationally focused view. Because the MSDD defines the system-design interrelationships, it becomes possible to holistically evaluate new design projects and to make total-cost decisions.

\section{Industrial application}

The following section explains in more detail step one of the combination of MSDD with the procedural design approach as shown in Figure 14. A plant that produces plastic bumpers wanted to redesign the material and information flow approach to ensure that the required quantity and mix of parts is made regardless of the variation in the manufacturing system. The manufacturing processes consist of injection molding, painting, and assembly. An automated storage and retrieval system stores the semi-finished products and delivers the parts to the next operation. The centralized production control department issues daily schedules for injection molding, paint, and assembly. The paint system is highly unreliable with fall-out rates between 10 and $60 \%$. As a result, there are several reviews of the production schedule every shift to adjust for the unreliability of the paint system.

The management of the plant initiated a project to schedule only final assembly. Paint and injection molding replenish the Standard Work In Process (SWIP) based on the consumption of material by assembly. Kanban cards are used to implement this approach. The goals of the new material replenishment method are to meet customer demand in spite of variation in the paint system and to achieve better visibility of the shop floor status. The company defined a low-volume product line to gain experience with the planned implementation with kanban. As a constraint, the company wanted to avoid major physical rearrangements in the plant and could not afford to invest in a new paint system. However, it was possible to reconfigure final assembly.

The MSDD was applied in a four-step process:

1. Determine the applicable FR's in the MSDD based on the project objectives 
2. Determine dependent FR's based on the interrelationships defined by the design matrices of the MSDD

3. Analysis of the existing system with respect to its achievement of the initial and dependent FR's

4. Analysis of existing system capabilities against FR's determined in steps 2 and 3

Translating the management objectives to FR's (step 1) was straightforward, since the mechanics of a kanban system are well known. The corresponding FR's are: FR-I2, "Eliminate information disruptions," FR-T3, "Reduce run size delay," FR-P11, "Ensure availability of relevant production information," FR-P14, "Ensure material availability," and FR-R111, "Identify disruptions when they occur." These FR's are shown as black boxes in Figure 17. The plant did not have SWIP prior to the project. The calculation of the necessary SWIP considered the high defect rate of paint and unpredictability of the equipment by using an extended base stock model [39].

Step 2 determines the prerequisites to achieve the stated requirements (shown as gray boxes in Figure 17). The prerequisites are determined either by following the decomposition to lower levels or by tracking the dependencies as stated in the design matrices of the MSDD. Two major new requirements became evident: clear definition of work standards to achieve predictable operator output (FR-P12), and balanced production (FR-T2). An operator is supposed to perform the kanban loop, which necessitates the achievement of stable operator output, i.e. easy handling of kanban cards to avoid loosing them and performing standard loops. Thus, the design of the interface between the kanban system and the operators became a critical design objective. Unpredictable operator output would almost certainly lead to higher standard WIP to satisfy material availability (FR-P14). 


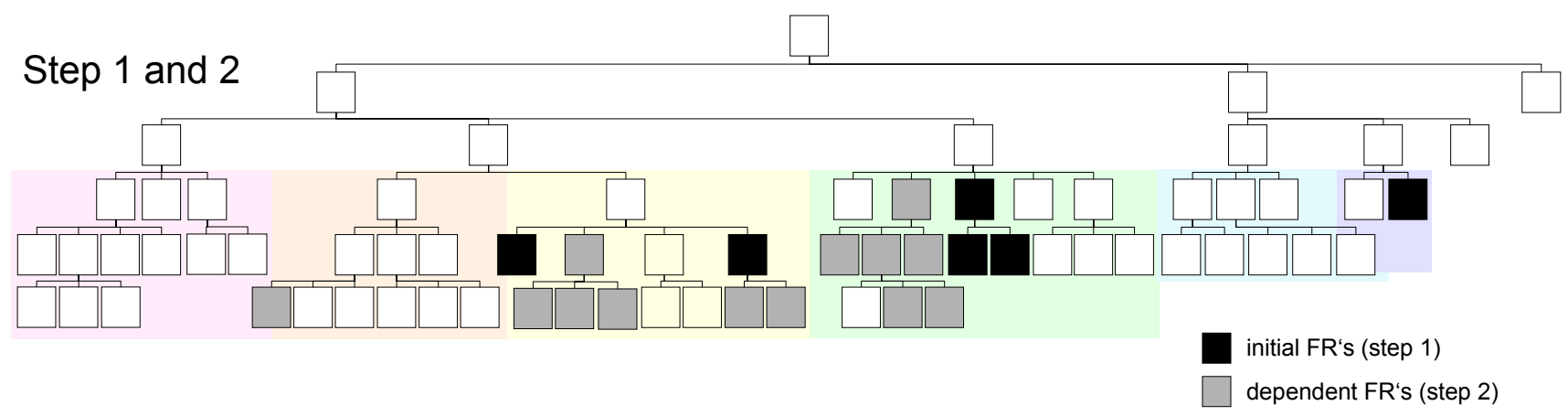

Figure 17: Initial design objectives are marked as black boxes. Dependent design objectives (gray boxes) are determined either by following the decomposition to lower levels or by tracking the dependencies as stated in the design matrices of the MSDD.

In step 3, the evaluation of the FR's and DP's of the MSDD has set off intensive discussions among the design team. The functional decomposition of the MSDD forced designers to think about the existing system from a different perspective and to consider a broad scope of system functions. Even though the relationship between poor predictability and throughput time is well understood, it may often be overlooked in design projects. The MSDD provided a common platform to develop cause and effect relationships previously not considered. The result of the analysis step is shown in Figure 18.

In step 4, the analysis shows three main areas of concern: stable operator output (FR-P12), material availability (FR-14), and reducing run size delay (FR-T3) as highlighted in Figure 18. The detailed design of the system put special emphasis on the mentioned areas. As a result, there is a dedicated operator performing the kanban loop. There may not be any interference with other operators to avoid any additional work tasks in the rest of the production (the pilot project covered only the lowest volume parts). A computer simulation was developed for the determination of the standard work in process. Furthermore, the plant uses a physical simulation, developed with the PSD lab, of the new system to train the operators and to illustrate the new information flow prior to the implementation of the system. 


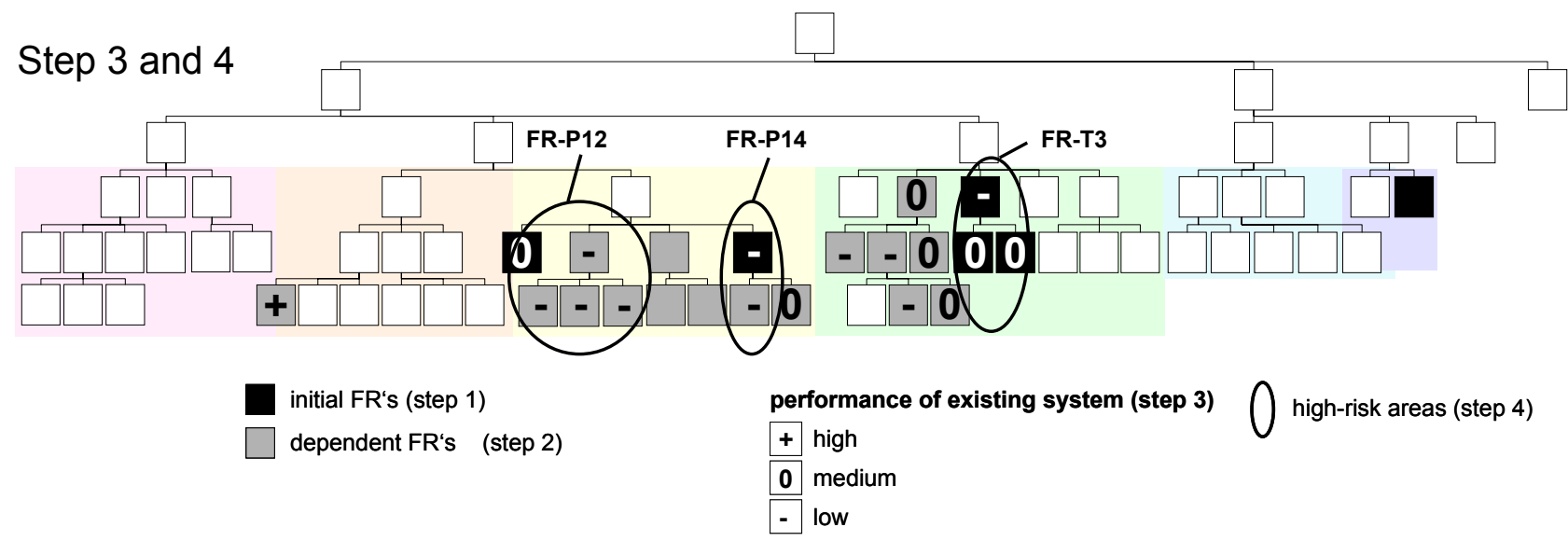

Figure 18: The MSDD was used to analyze the performance of the existing system relative to the FR's determined in step 1 and 2.The circled areas indicate main areas of concern.

Implementing a kanban system seems to be straightforward from the conceptual point of view. However, the analysis of the objectives using the MSDD revealed the multi-facets of a kanban system, which must be considered for a successful implementation. Thus, the MSDD provides a framework to determine critical design objectives that must be satisfied for a successful implementation. Note that the company was not capable of satisfying the requirements on the left side of the MSDD namely high quality processes (FR-111) and predictable resources (FR-112). However, the initial design objectives mostly focused on the elements on the right side of the MSDD (reduce run size delay and elimination of information disruptions (FR-I2)). Solving this conflict demanded standard levels of work in process to buffer for variability and quality problems.

The MSDD proved to be a very useful approach for analyzing the existing system, structuring the redesign project, and providing a communication platform among the various members of the design team.

\section{Conclusions and Outlook}

This paper has presented an axiomatic design-based decomposition of a general set of functional requirements and design parameters for a manufacturing system. This decomposition applies to a wide variety of manufacturing systems in different competitive environments. It is particular suitable for medium to high volume repetitive manufacturing. Other similar frameworks reviewed do not match objectives to means when relating low-level design decisions to higher-level system objectives. The use of the principles of axiomatic design was also reviewed, with an emphasis on the structured 
decomposition process it provides. The resulting decomposition has been found to be a useful approach for:

(1) Understanding the relationships between high level system objectives (increasing customer satisfaction, reducing system throughput time, etc.) and lower-level design decisions (equipment design and selection, system layout, etc.)

(2) Understanding the interrelations, precedence, and dependencies among various elements of a system design that determine its ability to meet high-level requirements and objectives.

Future work must combine the approach presented with existing manufacturing system design tools such as those discussed in the integration section. Since the MSDD covers many different aspects of manufacturing systems, a foundation has been developed to integrate a wide diversity of systems engineering design tools. While the MSDD states interrelationships between design solutions and design objectives, it is also desirable to quantify these interrelationships. Additional work has been done to associate performance measurables with each functional requirement of the MSDD (Cochran et al., 2000a).

\section{References}

[1] Hayes, R.H. and Wheelwright, S.C. (1979), "Link manufacturing process and product lifecycles", Harvard Business Review, January-February

[2] Shingo, S. (1988), Non-Stock Production: The Shingo System for Continuous Improvement, Productivity Press, Cambridge, MA.

[3] Hopp, W. and Spearman, M. (1996), Factory Physics, Irwin/McGraw-Hill, Boston, MA.

[4] Chryssolouris, G. (1992), Manufacturing Systems: Theory and Practice, Springer-Verlag, New York.

[5] Wu, B. (1992), Manufacturing Systems Design and Analysis, second edition, Chapman and Hall, London.

[6] Cochran, D. S. (1994), The Design and Control of Manufacturing Systems, Ph.D. Thesis, Auburn University.

[7] Spear, S. and Bowen, H.K. (1999), "Decoding the DNA of the Toyota production system," Harvard Business Review, September - October, pp. 97-106. 
[8] Zipkin, P.H. (1991), “Does manufacturing need a JIT revolution?” Harvard Business Review, January-February, pp. 4-11.

[9] Hayes, R.H. and Pisano, G.P. (1993), "Beyond world-class: the new manufacturing strategy", Harvard Business Review, January-February, pp. 77-86.

[10] Shingo, S. (1989), A Study of the Toyota Production System from an Industrial Engineering Viewpoint, Productivity Press, Cambridge, MA.

[11] Arinez, J.F. and Cochran, D.S. (2000), “An Equipment Design Approach To Achieve Production System Design Requirements," Proceedings of the 33rd CIRP International Seminar on Manufacturing Systems, June 5-7, Stockholm, Sweden.

[12] Senge, P.M. (1990), The Fifth Discipline: The Art and Practice of the Learning Organization, 1st ed., Doubleday/Currency.

[13] Miltenburg, J. (1995), Manufacturing Strategy - How to Formulate and Implement a Winning Plan, Productivity Press, Portland, OR.

[14] Gilgeous, V. and Gilgeous, M. (1999), “A Framework for Manufacturing excellence”, Integrated Manufacturing Systems, September, pp. 33-44.

[15] Monden, Y. (1993), Toyota Production System - An Integrated Approach to Just-In-Time, second edition, Industrial Engineering and Management Press, Norcross, GA.

[16] Melnyk, S.A.; Carter, P.L.; Dilts, D.M.; Lyth, D.M.; Shop Floor Control, Dow Jones-Irwin, 1985

[17] Wu, Bin (2000), Manufacturing and Supply Systems Management: A Unified Framework of Systems Design and Operation, New York : Springer, 2000

[18] Hitomi, K. (1996), Manufacturing Systems Engineering, Taylor and Francis, 2nd edition, 1996

[19] Meller, R.D.; Gau, K.-Y. (1996), "The Facility Layout Problem: Recent and Emerging Trends and Perspectives", Journal of Manufacturing Systems, 1996, 15, 5, pp. 351

[20] Reynal, V. and Cochran, D.S. (1997), “Axiomatic Design of Manufacturing Systems,” The Second World Congress of Intelligent Manufacturing Processes and Systems, June 10-13, Budapest, Hungary.

[21] Carrus, B.J. and Cochran, D.S. (1998), “Application of a Design Methodology for Production Systems," Proceedings of the EDA 98 Conference, July, Maui, Hawaii. 
[22] Suh, N.P., Cochran, D.S., and Lima, P.C. (1998) "Manufacturing system design", $48^{\text {th }}$ General Assembly of CIRP, Annals of CIRP, Vol. 47, No. 2, pp. 627-639.

[23] Cochran, D.S. (1999), “The Production System Design and Deployment Framework,” Proceedings of the 1999 SAE International Automotive Manufacturing Conference SAE Technical paper 1999-01-1644, May 11-13, Detroit, U.S.A.

[24] Suh, N.P. (1990), The Principles of Design, Oxford University Press, New York.

[25] Tate, D. (1999), A Roadmap for Decomposition: Activities, Theories, and Tools for System Design, Ph.D. Thesis, Massachusetts Institute of Technology.

[26] Clausing, D. (1994) Total Quality Development: : A Step-By-Step Guide to World Class Concurrent Engineering, American Society of Mechanical Engineers.

[27] Mayer, R.J., J.W. Crump, R. Fernandes, A. Keen, and M.K. Painter (1995), Information Integration for Concurrent Engineering (IICE) Compendium of Methods Report, Wright Patterson Air Force Base Interim Technical Paper, [Online] Available: http://www.idef.com/downloads/rtf/compendium.rtf [May 10, 2000].

[28] Johnson, H.T. and Kaplan, R.S. (1987), Relevance Lost - The Rise and Fall of Management Accounting, Harvard Business School Press, Boston, MA.

[29] Ferdows, K. and De Meyer, A. (1990), "Lasting improvements in manufacturing performance: in search of a new theory," Journal of Operations Management, Vol. 9, No. 2, pp. 168-184.

[30] Fillippini, R., Forza, C., and Vinelli, A. (1998), “Trade-off and compatibility between performance: definitions and empirical evidence," International Journal of Production Research, Vol. 36, No. 12, pp. 3379-3406.

[31] ReFa (1993), Arbeitsgestaltung in der Produktion, Hanser-Verlag.

[32] Grote, G., Ryser, C., Wäfler, T., Windischer, A., and Weik S. (2000), "KOMPASS: A method for complementary function allocation in automated work systems," International Journal of Human-Computer Studies, February, Vol. 52, no. 2.

[33] Nakajima, S. editor (1989), TPM development program : implementing total productive maintenance, Productivity Press. 
[34] Duda, James W. (2000), A Decomposition-Based Approach to Linking Strategy, Performance Measurement, and Manufacturing System Design, Ph.D. Thesis, Massachusetts Institute of Technology

[35] Arinez, Jorge F.(2000), An Equipment Design Approach for Achieving Manufacturing System Design Requirements, Ph.D. Thesis, Massachusetts Institute of Technology

[36] Cochran, D.S., Linck, J., Reinhart, G., and Mauderer, M. (2000), “Decision Support For Manufacturing System Design - Combining A Decomposition Methodology With Procedural Manufacturing System Design," Proceedings of the Third World Congress on Intelligent Manufacturing Processes and Systems, June 28-30, Boston, MA.

[37] Kettner H., Schmidt J., and Greim H.-R. (1984), Leitfaden der systematischen Fabrikplanung, Carl Hanser Verlag München Wien

[38] Cochran, D.S., Kim, J., Kim, Y.-S. (2000), "Performance Measurement and Manufacturing System Design," Proceedings of the 33rd CIRP International Seminar on Manufacturing Systems, June 5-7, Stockholm, Sweden.

[39] Graban, Mark R. (1999), An inventory planning methodology for a semiconductor manufacturer with significant sources of variability, Master Thesis, Massachusetts Institute of Technology.

\section{Authors' Biographies}

David Cochran is an Associate Professor of Mechanical Engineering at MIT. He received his Ph.D. in Industrial and Manufacturing Systems Engineering from Auburn University and a M.Sc in Manufacturing Engineering from The Pennsylvania State University. He is founder and director of the Production System Design Laboratory, an initiative within the Laboratory for Manufacturing and Productivity, to develop a comprehensive approach for the design and implementation of production systems. He is a two-time recipient of the Shingo Prize for Manufacturing Excellence (2002 and 1989), and has also received the Dudley Prize for best paper from the International Journal of Production Research in 2000 for his work to integrate system design theory. Prior to joining MIT, Dr. Cochran worked with Ford Motor Company.

Jorge F. Arinez holds a Ph.D. and S.M. degree in mechanical engineering from the Massachusetts Institute of Technology. He also received a B.A.Sc degree in mechanical engineering from University of Toronto. He currently working for General Motors in their Research \& Development Center. 
James W. Duda holds a Ph.D. and M.S. degree in mechanical engineering from the Massachusetts Institute of Technology. He also received a B.S. degree in mechanical engineering from Case Western Reserve University. He is working with i2 Technologies.

Joachim Linck holds a Ph.D. from the Department of Mechanical Engineering at MIT. He also holds a diploma in mechanical engineering from Technical University of Aachen, Germany. He is working with McKinsey \& Company's Manufacturing Practice in Germany. 


\section{Appendix A}

\section{Manufacturing System Design Decomposition v5.3 (page 1 of 2)}

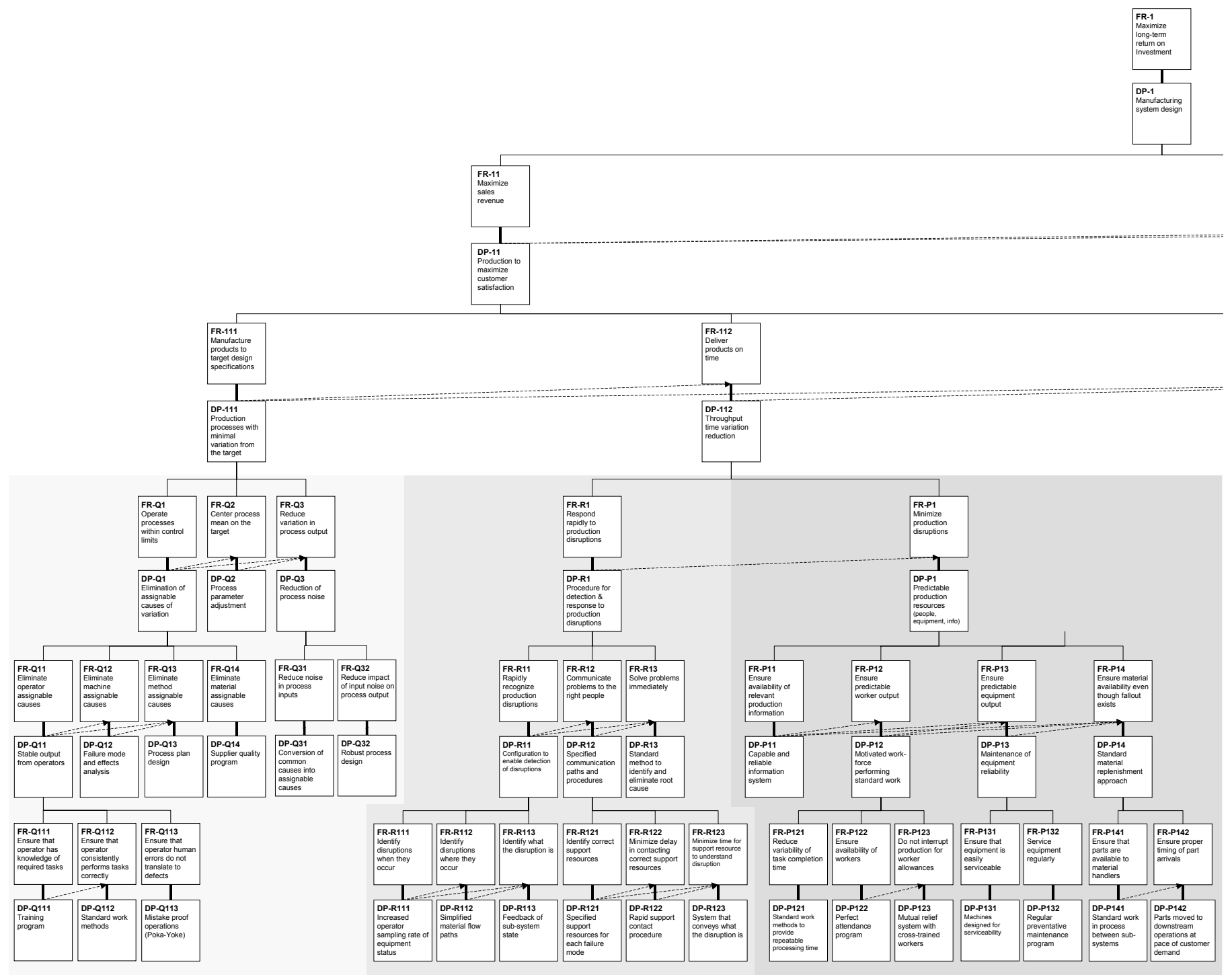


Manufacturing System Design Decomposition v5.3 (page 2 of 2)

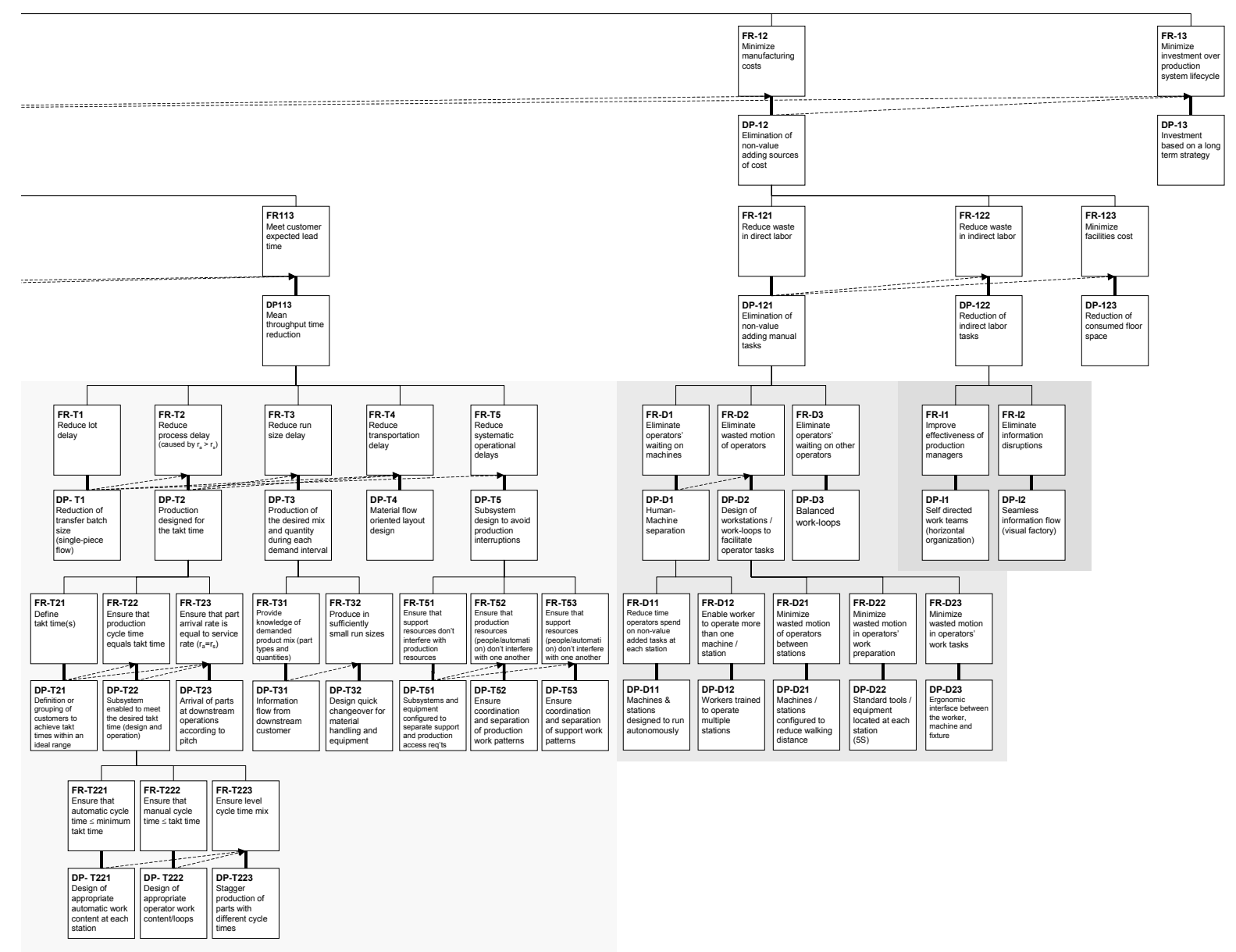

